\title{
A Cross-Sectional Observational Study on Impact of Covid-19 Pandemic on Mental Health and Quality of Life in Different Socioeconomic Groups in India
}

\author{
Shreyansh R. Rai*1, Dwivedi Anuj Sugreev ${ }^{1}$, Tiwari Pradhyuman ${ }^{1}$, Snigdha Das Mandal ${ }^{2}$, G.S. Chakraborthy ${ }^{3}$ \\ 1. Doctor of Pharmacy, Parul Institute of Pharmacy \& Research, Parul University, Vadodara, Gujarat- 391760, India. \\ 2. Department of Pharmacology, Parul Institute of Pharmacy \& Research, Parul University, Vadodara, Gujarat- 391760, India. \\ 3. Professor and Principal, Parul Institute of Pharmacy \& Research, Parul University, Vadodara, Gujarat- 391760, India. \\ *Corresponding author's E-mail: raishreyansh19@gmail.com
}

Received: 16-03-2021; Revised: 22-05-2021; Accepted: 27-05-2021; Published on: 15-06-2021.

\section{ABSTRACT}

The corona virus disease (COVID-19) is expected to have widespread and persuasive implication for mental health and financial status in terms of deteriorating outcomes and increased health service use that leading to call for empirical research on mental health during pandemic. The aim of study is to assess the Impact of COVID-19 Pandemic on Mental Health and Quality of Life in Different Socioeconomic Groups in India. An online study was conducted through Google Forms and the link was sent to participants via WhatsApp, Facebook, Instagram \& one-to-one interview was done. A self-designed questionnaire survey was utilized for the study. Total 476 responses were obtained. A total of 476 participants were belonged to different social groups where $82(17.2 \%)$ were homemakers, $127(26.7 \%)$ were from job sector and $254(53.4 \%)$ were students \& $13(2.7 \%)$ were others. The most affected group in term of anxiety score were home-makers where $39 \%$ had moderate anxiety \& $25.6 \%$ had severe anxiety. Other were different economic classes where 20 (4.2\%) from BPL, 186 (39.1\%) from Lower-middle class, 224 (47.1\%) from Upper-middle class \& 46 (9.7\%) from Upper class. The most affected in terms of facing financial crisis were $85 \%$ from BPL class. And score of anxiety level where mild anxiety was most in lower-middle class (44.6\%), moderate anxiety was seen in BPL class $(60 \%)$ \& severe anxiety in Upper class $(28.8 \%)$. The pandemic had affected people across different social \& economical groups financially as well as mentally to a significant level.

Keywords: COVID-19, Pandemic, Financial, Psychological, Socioeconomic.

QUICK RESPONSE CODE $\rightarrow$

DOI:

10.47583/ijpsrr.2021.v68i02.018

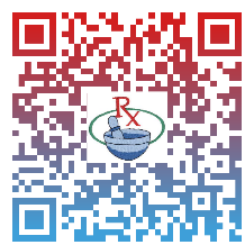

DOI link: http://dx.doi.org/10.47583/ijpsrr.2021.v68i02.018

\section{INTRODUCTION}

T he COVID-19 Pandemic has emerged as an awfully real threat to global health, economic stability, and the way different societies and government's function ${ }^{1}$.The impact of the pandemic on health systems, worsening economy, high unemployment rates, widespread social barriers, isolation and the constant delivery of confronting news from the media are unprecedented challenge for population ${ }^{2}$. The populations may have experienced some known risk factors for depression and anxiety including high death rate, resource and food insecurities, intolerance, which may result in some adverse mental state outcomes during this pandemic ${ }^{3}$. The COVID-19 pandemic provides a unique opportunity to study the psychological impact of the condition, which in turn poses a high risk of infectious disease, threatens the integrity of the physical and psychological balance of people, and in the long run has a significant socio-psychological impact. It also provides an opportunity to explore the psychological impact of an administrative decision as rare as "lockdown" on general population ${ }^{4}$. Based on data from a study examining the impact of academic disruption on students, it is reasonable to venture that students may experience reduced academic motivation, increased pressures for independent study, abandonment of daily routines, and higher student dropout rates as a direct consequence of these measures ${ }^{5}$. Evidence suggests that there is a direct relationship between mental health and sleep quality, an important public health problem. In this study, we aimed to assess stress, sleep quality, and Quality of Life (QoL) related to the health of people with multiple problems other than multiple health problems during home isolation in India due to the COVID-19 pandemic ${ }^{6}$. In addition to the physical and mental health effects of COVID-19, it has the gendered impact that includes additional responsibilities born by women, including; care for family members, house hold chores and home schooling ${ }^{7}$. The socioeconomic effect of pandemic has squeezed and put enormous pressure on individual, family and community levels ${ }^{8}$. An impact appraisal based on accessible literature is made on all the three sectors - primary, secondary and service sector alongside the impact on transients, health, destitution, work misfortunes, informal sector, environment, etc. All sector of the economy has been excessively influenced and even within a sector, there is disproportionate loss ${ }^{9}$. This study will address these challenges and increase the capacity and availability of support to government, healthcare professionals, local communities and civic 
organization to increase source of knowledge for better decision making and counsel the people who are affected psychologically and financially according to their socioeconomic classes.

\section{MATERIALS AND METHODS}

\section{Study Preparation}

A cross-sectional observational survey design was decided to assess the impact of COVID-19 pandemic on mental health and quality of life in different socioeconomic groups in India.

\section{Data Collection}

The survey was conducted through online platform (Google form) which was conveyed through social media handles of investigators and one-to-one interview was done for participants from weaker socioeconomic section.

\section{Sample Selection Criteria}

The survey was conducted in English language, therefore people who had access to internet and known to English language were included. One-to-one interview was done in vernacular language for people willing to participate in study from weaker socioeconomic category who don't use social media. The survey was conducted during August 2020- October 2020. The data collected was analysed using IBM SPSS (25.0) software and Microsoft Excel.

\subsection{Data Analysis and Statistical Application:}

The data collected were socioeconomic details, score of anxiety levels in different socioeconomic groups, levels of financial crisis in different economical groups, stress \& pressure on students, increased workload on homemakers, and deteriorating quality of life during pandemic in different groups.

\section{RESULTS}

\section{Socioeconomic details}

A total of 476 participants were belonged to different social groups where $82(17.2 \%)$ were home-makers, 127 (26.7\%) were from job sector and 254 (53.4\%) were students \& $13(2.7 \%)$ were others. Other were different economic classes where 20 (4.2\%) from BPL, 186 (39.1\%) from Lower-middle class, 224 (47.1\%) from Upper-middle class \& 46 (9.7\%) from Upper class.

Table 1: Effect of pandemic \& Activities of daily life on participants from different economic classes

\begin{tabular}{|c|c|c|c|c|c|c|}
\hline \multirow{2}{*}{$\begin{array}{l}\text { Economic } \\
\text { Classes }\end{array}$} & \multicolumn{2}{|c|}{ Sleep Cycle } & \multicolumn{4}{|c|}{ Activities of daily life affected } \\
\hline & Normal & Disturbed & Little Bit & Much Work & Most Work & None \\
\hline Upper class & $27(58.7 \%)$ & $19(41.3 \%)$ & $32(69.6 \%)$ & $4(8.7 \%)$ & $9(19.6 \%)$ & $1(2.2 \%)$ \\
\hline $\begin{array}{c}\text { Upper- } \\
\text { middle class }\end{array}$ & $130(57.5 \%)$ & $96(42.5 \%)$ & $172(76.1 \%)$ & $16(7.1 \%)$ & $30(13.3 \%)$ & $8(3.5 \%)$ \\
\hline $\begin{array}{l}\text { Lower- } \\
\text { middle class }\end{array}$ & 95 (51.6\%) & $89(48.4 \%)$ & $122(66.3 \%)$ & $9(4.9 \%)$ & 47 (25.5\%) & $6(3.3 \%)$ \\
\hline BPL class & $8(40.0 \%)$ & $12(60.0 \%)$ & $3(15.0 \%)$ & $1(5.0 \%)$ & $15(75.0 \%)$ & $1(5.0 \%)$ \\
\hline
\end{tabular}

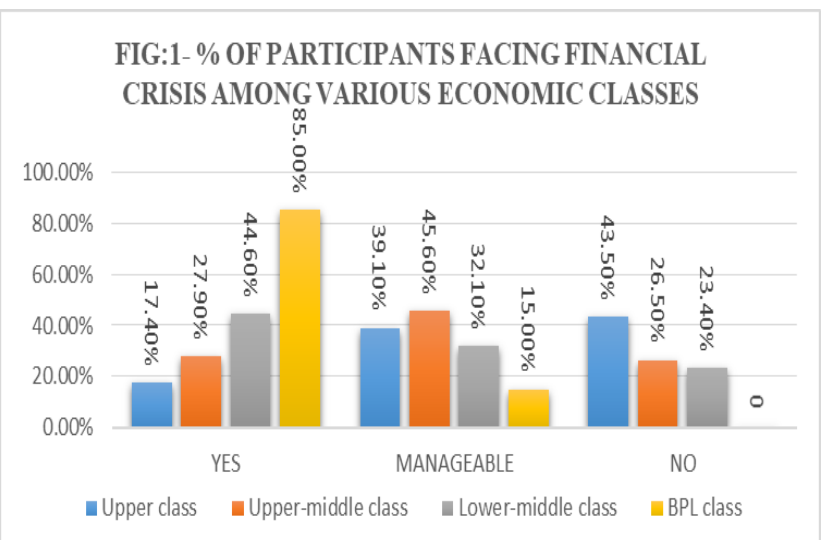

Financial crisis across different economic classes where most affected were BPL class with 17 (85\%), other who said it was manageable and most were from upper-middle class with 103 (45.6\%).

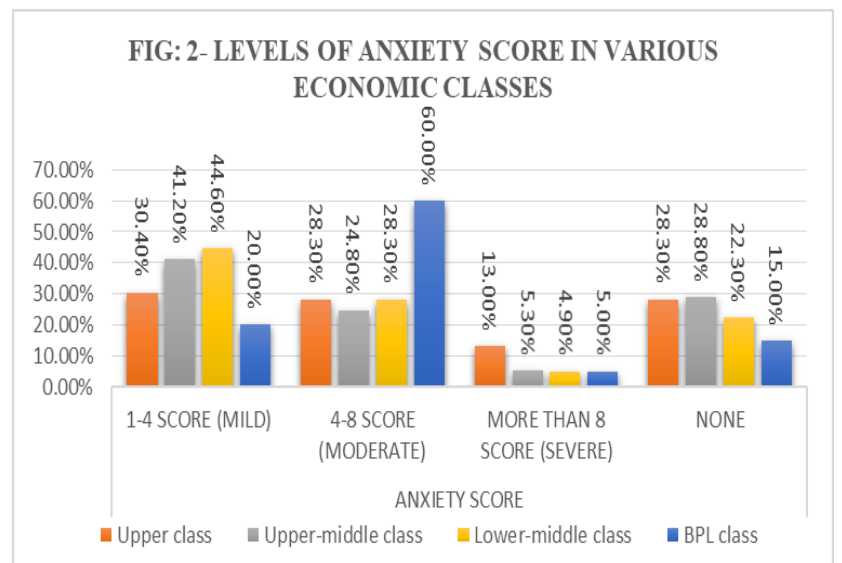

Anxiety score among different economic class where 1-4 score (mild anxiety) was most seen in lower-middle class with 82 (44.6\%), 4-8 score (moderate anxiety) was most in BPL class with $12(60 \%)$, more than 8 score (severe) was in upper class with 6 (13\%). 


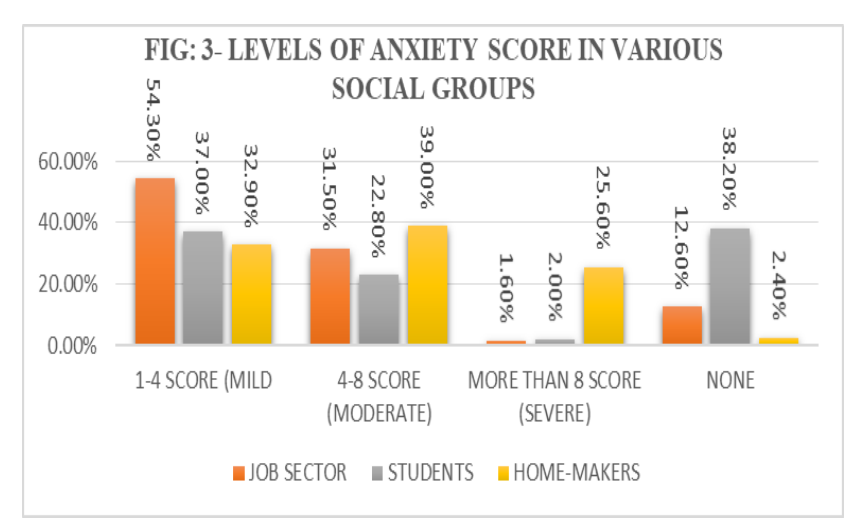

Anxiety score among different social groups where 1-4 score (mild anxiety) was mostly seen in people from job sector that is 69 (54.3\%), then $4-8$ score (moderate anxiety) was most in home-makers that is $32(39 \%)$ and more than 8 score (severe anxiety) were also most in home-makers that is $21(25.6 \%)$.

\section{DISCUSSION}

The effect of the pandemic on wellbeing frameworks, demolishing economy and relatively high paces of joblessness, the far reaching social limitations and isolation, and furthermore the psychological condition of individuals of the country. Additionally, the populations may have experienced some known risk factors for depression and anxiety including high death rate, resource and food insecurities, discrimination, and skill with infected and sick individuals, which may result in some adverse mental state outcomes during this pandemic ${ }^{3}$.The monetary impact has crushed individual, family and neighbourhood. A couple of nations used money related measures to diminish the predicted monetary slump.

Sample population is divided into different social groups i.e. participants from job sectors, students, home-makers \& economic classes as per there annual income i.e. Upper class, Upper-middle class, lower-middle class, BPL (Below Poverty Line). This pandemic had hit people's financial situation severely which ultimately caused disruption of daily needs and causing deficiency of basic amenities like food.

Pandemic \& lockdown caused a heavy toll on jobs and daily wage workers. Economic activities came to halt, Fig.1. depict those who were facing financial crisis from different levels were 8 (17.4\%) from upper class, 63 (27.9\%) from upper-middle class, 82 (44.6\%) from lower middle class and 17 (85.0\%) from BPL class. There are many people who said that though they were facing financial issues but it was manageable and they were 18 (39.1\%) from upper class, 103 (45.6\%) from upper-middle class, 59 (32.1\%) lowermiddle class and $3(15.0 \%)$ from BPL class. This indicates the most affected were from BPL and Lower-middle families dealing with the financial problems.

As per different economic class and different levels of anxiety score. Assessing data fig.2. which shows that mild stress were most seen in lower-middle class were 82 $(44.6 \%)$ and then upper-middle class were 93 (41.2\%), which both in the middle classes most people were experiencing mild anxiety. Moderate anxiety (4-8 score) were mostly seen in BPL class with highest 12 (60\%) and then lower-middle class with 52 (28.3\%). Then comes the severe anxiety level (more than 8 score) where attention and care is needed which was seen most in upper class affecting 6 (13.0\%) people from them.

Effect on students: Being all day home and getting started with different mode of education already stressed students, adding parent's pressure for studies as they were also more tensed about future of their children they became more prone to stress issues. And among 254 students 124 (48.8\%) admitted that they sometimes felt more pressurized, 17 $(6.7 \%)$ they got pressurized all the time for studies. The pandemic created uncertainty about future and many questions in their mind and when asked about whether they were worried or not, about 214 (84.3\%) said yes that they were worried about their future and studies while only $40(15.7 \%)$ said that they were not worried. So significantly large number of students were affected.

In Fig.3. talking about stress and anxiety score across different social groups that is people from job sectors, students and home-makers. Starting from 1-4 score (mild anxiety) $54.3 \%$ were from job sector, $37.0 \%$ were students and $32.9 \%$ were home-makers. With more anxiety $4-8$ score (moderate anxiety) 31.5\% were from job sector, $22.8 \%$ are students and $39.0 \%$ are home-makers. Then with more than 8 score (severe anxiety) are $1.6 \%$ from job sectors, $2.0 \%$ are students and $25.6 \%$ are home-makers. The home-makers or mostly women were under severe stress with of all levels followed by people from job sectors with mild or moderate stress. On other hand students have mixed type of response where about $37 \%$ having mild anxiety issues, while $38 \%$ were also don't have any anxiety issues.

Pandemic induced lockdown and constant fear of infection where environment was full of terror due to virus. Living in such conditions added stress and caused disturbed sleep cycle in many people among them19 (41.3\%) from upper class, 96 (42.5\%) from upper-middle class, 89 (48.4\%) from lower-middle class and 12 (60.0\%) from BPL class. Activities of daily life were heavily affected during this pandemic. Respondents were asked about different level. They said that only little bit affected were32 (69.6\%) from Upper class, 172 (76.1\%) from upper- middle class, 122 (66.3\%) from lower-middle class and $3(15.0 \%)$ from BPL. Then comes where much work is affected $4(8.7 \%)$ from upper class, 16 (7.1\%) from upper-middle class, 9 (4.9\%) from lower-middle class and 1 (5.0\%) from BPL class. Then those whose daily work was most affected were 9 (19.6\%) from upper class, 30 (13.3\%) from Upper-middle class, 47 (25.5\%) from lower-middle class and 15 (75.0\%) from BPL class.

\section{CONCLUSION}

The COVID-19 pandemic poses a serious medical challenge to mankind. The socioeconomic impact of the pandemic is expected to last a long time. The disease has led to unprecedented losses globally but India being an emerging 
economy is likely to be severely affected in all sectors and that is not very equitable. Our study revealed that proportion of the participants were depressed and had some psychological impact as a result of the pandemic in India. The analysis was performed at various socioeconomic levels and it was predicted that most of them had financial problems and stress, felt depressed, anxious and had challenges in family. The findings of our study highlight a number of factors that contribute to students' distress during this pandemic; however, there is still much to learn about the psychological implications of students and what can be done to cope up with their negative effects. The result clearly shows the deterioration of mental health outcomes in various socioeconomic classes and in other sectors during COVID-19. Although further research is needed, the findings of our study support the mental health implication of this pandemic and emphasize the use of internet-based data collection tools to provide evidence to innovate and strengthen performance and policy during and after the pandemic.

\section{STRENGTHS OF STUDY}

- This study could assist health care professionals as well as government bodies to know the mental and economical stress, on different classes of societies such as Upper class, upper middle, lower-middle and BPL families.

-This study also help to assess the mental health issues faced by different groups of people during COVID-19 pandemic such as people in job sector, homemakers and students.

Acknowledgments: We acknowledge all participants who showed interest in the survey and responded for study.

\section{REFERENCES}

1. Mack Sheraton, Neha Deo, Taru Dutt, Salim Surani, Daniel Hall-Flavin, Rahul Kashyap, Psychological effects of the COVID 19 pandemic on healthcare workers globally: A systematic review, Psychiatry Research, 2020;292:113360, https://doi.org/10.1016/j.psychres.2020.113360.

2. Van Agteren J, Bartholomaeus J, Fassnacht DB, lasiello M, Ali K, Lo L, Kyrios M Using Internet-Based Psychological
Measurement to Capture the Deteriorating Community Mental Health Profile During COVID-19: Observational Study JMIR Mental Health 2020;7(6):e20696. doi: 10.2196/20696.

3. Zhang Y, Ma ZF. Impact of the COVID-19 Pandemic on Mental Health and Quality of Life among Local Residents in Liaoning Province, China: A Cross-Sectional Study. Int J Environ Res Public Health. 2020 Mar 31;17(7):2381. doi: 10.3390/ijerph17072381. PMID: 32244498; PMCID: PMC7177660.

4. Chakraborty K, Chatterjee M. Reply to the comments on "Psychological impact of COVID-19 pandemic on general population in West Bengal: A cross-sectional study". Indian Journal of Psychiatry. 2020;62(4):448.

5. Policy brief: COVID-19 and the need for action on mental health [Internet]. Unsdg.un.org. [cited 2021 Mar 5]. Available from: https://unsdg.un.org/resources/policybrief-covid-19-and-need-action-mental-health.

6. Patra RC, Kanungo B and Bawa P. Mental health, sleep quality and quality of life in individuals with and without multiple health conditions during home quarantine in India due to the COVID-19 pandemic: a cross-sectional study [version 1; peer review: 1 approved]. F1000 Research 2020, 9:718 (https://doi.org/10.12688/f1000research.24321.1.)

7. Viveiros, N., Bonomi, A.E. Novel Coronavirus (COVID-19): Violence, Reproductive Rights and Related Health Risks for Women, Opportunities for Practice Innovation. J Fam Viol (2020). https://doi.org/10.1007/s10896-020-00169-x.

8. Pillai DDM, Nagappan N, Dharani SV, Subramanian K, Champakesan B, D'Cruz TM. Socio-economic impact of coronavirus disease 2019 (COVID-19) - An Indian outlook. J Family Med Prim Care. 2020 Oct 30;9(10):5103-5106. doi: 10.4103/jfmpc.jfmpc_835_20. PMID: 33409171; PMCID: PMC7773074.

9. Aneja R, Ahuja V. An assessment of socioeconomic impact of COVID-19 pandemic in India. J Public Aff. 2020;e2266.

Source of Support: The author(s) received no financial support for the research, authorship, and/or publication of this article.

Conflict of Interest: The author(s) declared no potential conflicts of interest with respect to the research, authorship, and/or publication of this article.

For any question relates to this article, please reach us at: editor@globalresearchonline.net New manuscripts for publication can be submitted at: submit@globalresearchonline.net and submit_ijpsrr@rediffmail.com 